\title{
Analisis Penyelenggaraan Puskesmas Tatalaksana Kekerasan terhadap Anak (KtA) dalam Penanganan Kekerasan Anak di Kota Padang
}

Nia Prima Shartika ${ }^{1}$, Husna Yetti ${ }^{2}$, dan Ikhsan Yusda PP ${ }^{3}$

\begin{abstract}
Abstrak
Kota Padang menjadi salah satu kota tertinggi kasus kekerasan anak dengan total 113 kasus, sehingga perlu peran dari semua phak dalam mengatasi hal ini, khususnya sektor kesehatan. Tujuan penelitian ini adalah melihat bagaimana pelaksanaan puskesmas tatalaksana Kekerasan terhadap Anak (KtA) yaitu Puskesmas Andalas, Puskesmas Anak Air dan Puskesmas Air Tawar dalam menangani masalah kekerasan terhadap anak di Kota Padang. Metode yang dipakai dalam penelitian adalah kualitatif dengan wawancara mendalam, Focus Group Discussion dan telaah dokumen. Ada 18 informan dari Dinas kesehatan dan Puskesmas KtA Kota Padang, Dinas Pendidikan, DP3AP2KB, P2tP2A, Polresta Padang dan keluarga anak korban kekekerasan. Hasil penelitian ini ialah Puskesmas $\mathrm{KtA}$ belum diperkuat oleh SK Walikota, masih kurangnya tenaga terlatih KtA, sarana prasarana serta dana juga masih kurang, dari proses pelaksanaan KtA masih belum mengikuti konsep manajemen pelaksanaan puskesmas KtA yang memberikan pelayanan secara komprehensif, serta belum adanya jejaring puskesmas KtA di Kota Padang. Simpulan studi ini ialah pelaksanaan puskesmas KtA oleh Puskesmas Andalas, Puskesmas Anak Air dan Puskesmas Air Tawar belum optimal dalam penanganan kekerasan terhadap anak di Kota Padang.
\end{abstract}

Kata kunci: puskesmas KtA, kekerasan anak, kualitatif

\begin{abstract}
the city of Padang is one of the highest number cases of child violence with a total of one hundred and thirteen cases, therefore the role of all people is needed to overcome this, especially the health sector. The objective of this study was to see how the implementation of the health center managed the violence against children, namely the Andalas Health Center, the Anak Air Health Center and the Air Tawar Health Center in dealing with the problem of violence against children in Padang City. The method used in this study was qualitative with in-depth interviews, Focus Group Discussion and documents. There were eighteen informants from the Head of Padang Health Office and The Violence againts Health Center in Padang City, Education Office, DP3AP2KB, P2tP2A, Padang Police and child abuse victims. The results of this study was the violence againts children health center has not been strengthened by the Mayor's Decree, there is still a lack of violence agiants children trained personnel, facilities and funds are still lacking, from the violence againts children implementation process it has not followed the KtA health center management concept that provides comprehensive services, and lack of violence againts children health center in the city of Padang. The conclusion is that the implementation of the violence againts children health center by Andalas Community Health Center, Anak Air Health Center and Air Tawar Health Center has not been optimal in handling violence against children in the city of Padang.
\end{abstract}

Keywords: violence againts children health center, child violence, qualitative 


\section{PENDAHULUAN}

Kekerasan terhadap anak merupakan semua bentuk tindakan, atau perlakuan yang dilakukan seseorang yang dapat menimbulkan sakit, penderitaan, seperti kekerasan fisik, kekerasan seksual, kekerasan emosional atau psikologis dan penelantaran $^{1}$ Permasalahan kekerasan terhadap anak di dunia juga pernah diteliti oleh Hillis et al (2016) yang berjudul "Global Prevalence Of Past Year Violence Againts Children: A Systematic Review and Minimum Estimates" dan hasilnya angka kekerasan tertinggi pada anak pada tahun 2014 terjadi di Asia. Ada lebih 714 juta atau 64 persen dari populasi anakanak di Asia mengalami setidaknya satu bentuk kekerasan berat. Jika kekerasan yang dinilai lebih ringan seperti memukul pantat dan menampar wajah ikut dihitung angkanya lebih besar lagi 888 juta anak atau setara $80 \%$ populasi anak di Asia. $^{2}$

Di Indonesia data kekerasan terhadap anak tersedia, permasalahan kekerasan pada anak seperti fenomena gunung es. Pada tahun 2013 Kementerian Sosial mengadakan Survey Kekerasan Terhadap Anak (SKTA) pada tahun 2013 yang menunjukkan hasil bahwa kekerasan yang dialami anak laki-laki lebih besar dibandingkan anak perempuan. Jumlahnya mencapai hampir separuh populasi anak laki-laki, yaitu $47,74 \%$, pada anak perempuan prevalensinya mencapai $17,98 \%$. Jika dilihat berdasarkan jenisnya anak-anak Indonesia cendrung mengalami kekerasan emosional dibandingkan fisik. Sebanyak $70,98 \%$ anak laki-laki dan $88,24 \%$ anak perempuan yang mengalami kekerasan fisik. Untuk kategori kekerasan emosional sebanyak $86,65 \%$ pada anak laki-laki dan $96,22 \%$ pada anak perempuan. Survei ini dilakukan pada 25 provinsi, 108 kabupaten/kota dan 125 kecamatan. $^{3}$

Data kekerasan pada anak di Sumatera Barat pada tahun 2017, terjadi 1.430 kasus kekerasan terhadap anak yang dilaporkan, dan 3 kabupaten dengan kasus pelaporan tertinggi adalah pertama Kabupaten Pasaman Barat sebanyak 154 kasus, kedua Kota Padang sebanyak 118 kasus dan ketiga adalah Kota Payakumbuh sebanyak 114 kasus. ${ }^{4}$

Kasus kekerasan pada anak di Kota Padang berdasarkan data dari unit Perlindungan Perempuan dan Anak Kota Padang untuk tahun 2016 kasus kekerasan pada anak sebanyak 57 kasus, dan terjadi peningkatan di tahun 2017 menjadi 78 kasus. Dari pengaduan tersebut kasus terbanyak yang dialami oleh anak di Kota Padang adalah kekerasan seksual. ${ }^{5}$

Kekerasan yang dialami anak-anak membawa dampak yang sangat serius, baik sekarang ataupun ketika anak sudah dewasa.Dampak kekerasan pada anak akan berpengaruh terhadap fisik, mental dan seksual seperti memar, lecet, luka bakar, patah tulang, kerusakan organ, robekan selaput dara, keracunan, gangguan syaraf, pusat, gangguan emosi atau perubahan perilaku, kecacatan, kehamilan tidak diinginkan (KTD), dan Infeksi Menular Seksual. ${ }^{6}$ Pada saat anak beranjak anak rentan menjadi remaja yang nakal $^{7}$. Kekerasan juga berdampak pada munculnya perilaku menyimpang Lelaki Seks Lelaki (LSL) disaat anak-anak dewasa. ${ }^{8}$

Upaya mengatasi permasalahan kekerasan terhadap anak, Pemerintah Indonesia telah meratifikasi Konvensi Hak Anak (KHA) Perserikatan Bangsa-Bangsa (PBB) melalui Keputusan Presiden nomor 36 tahun 1990, Konsekuensinya pemerintah harus menyelenggarakan seluruh kegiatan dalam upaya perlindungan bagi anak Indonesia yang mengacu pada empat prinsip dasar KHA, yaitu non diskriminasi, kepentingan terbaik bagi anak, kelangsungan hidup dan tumbuh kembang, serta penghargaan terhadap pendapat anak. Dengan demikian semua sektor harus memberikan kontribusi nyata sesuai dengan tugas pokok, fungsi, peran masing-masing ${ }^{9}$

Peraturan Menteri Kesehatan (Permenkes) nomor 68 tahun 2013 yang mengatur tentang kewajiban pemberi pelayanan kesehatan untuk memberikan informasi apabila terjadi dugaan kekerasan anak berkewajiban melaporkan kepada kepolisian, dalam hal ini unit Perlindungan Perempuan dan Anak (UPPA) yang ada diseluruh Polres/ Polwil/ Polda, apabila tidak melaporkan bisa terancam mendapatkan sanksi. ${ }^{10}$

Sektor kesehatan yang juga ikut terlibat dalam upaya penanganan kekerasan pada anak, melalui Rencana Strategis Nasional Kesehatan tahun 20102014 telah ditetapkan bahwa indikator program KtA adalah setiap kabupaten/ kota harus memiliki minimal 2 (dua) puskesmas yang mampu penatalaksanaan 
KtA berupa upaya preventif, promotif, kuratif dan rehabilitatif dalam penanganan kekerasan terhadap anak. Puskesmas tersebut juga mempunyai tenaga kesehatan yang mengikuti pelatihan khusus mampu tatalaksana kekerasan terhadap anak yang diselenggarakan oleh Kementrian Kesehatan melalui Dinas Kesehatan Provinsi. ${ }^{9}$

Pelayanan kesehatan bagi korban KtA dilakukan melalui pelayanan di tingkat dasar yaitu di puskesmas maupun pelayanan rujukan di tingkat rumah sakit melalui Pusat Pelayanan Terpadu (PPT) atau Pusat Krisis Terpadu (PKT) baik di rumah sakit umum daerah, Rumah Sakit Bhayangkara maupun di rumah sakit swasta. Dalam upaya optimalisasi penanganan kasus kekerasan pada anak Kota Padang juga telah memiliki 3 (tiga) puskesmas tata laksana KtA yaitu Puskesmas Air Tawar, Puskesmas Andalas dan Puskesmas Anak Air. ${ }^{11}$

Berdasarkan uraian di atas membuat penulis tertarik untuk meneliti bagaimana penyelenggaraan puskesmas tata laksana $\mathrm{KtA}$ dalam penanganan kasus kekerasan pada anak di Kota Padang.

\section{METODE}

Rancangan dalam penelitian ini menggunakan jenis penelitian kualitatif, yang bertujuan untuk mendapatkan gambaran secara mendalam tentang pelaksanaan pelaksanaan puskesmas tatalaksana KtA (Puskesmas Andalas, Puskesmas Anak Air, Puskesmas Air Tawar) dalam penanganan kasus kekerasan terhadap anak di Kota Padang dimulai dari bulan Maret 2018 sampai dengan Juli 2018. Informan dalam penelitian ini adalah Walikota Padang, Kepala Dinas Kesehatan Kota Padang, Kepala Seksi KIA DKK Padang, Kepala Puskesmas dan penanggung jawab program KtA Puskesmas Andalas, Puskesmas Anak Air, Puskesmas Air Tawar, Kepala Dinas Pendidikan Kota Padang, Kepala Seksi Perlindungan Anak DP3AP2KB, Direktur RSUD Dr.Rasidin Kota Padang, Ketua P2TP2A Kota Padang, Ka. Unit UPPA Polresta Padang, Anak Korban Kekerasan serta masyarakat beresiko di wilayah kerja Puskesmas Mampu Tatalaksana KtA Kota Padang. Alat yang digunakan dalam penelitian ini adalah pedoman wawancara, pedoman FGD, lembar observasi, telaah dokumen, tape recorder dan kamera. Sumber data terdiri dari data primer dan data sekunder ${ }^{-12}$

Sumber data primer terdiri dari hasil observasi langsung penyelenggaraan puskesmas tatalaksana $\mathrm{KtA}$, hasil wawancara mendalam dengan informan dan hasil Focus Group Discussion. Data sekunder didapat dari sumber tertulis berupa dokumen terkait penyelanggaraan puskesmas tatalaksana KtA di Kota Padang.

\section{HASIL}

\section{Komponen input}

a. Kebijakan

Kebijakan yang dipakai sebagai dasar penyelenggaraan puskesmas KtA adalah SK Kepala Dinas Kesehatan Kota Padang tahun 2016 tentang penetapan Puskesmas Andalas, Puskesmas Anak Air, dan Puskesmas Air Tawar sebagai puskesmas tatalaksana KtA di Kota Padang, namun SK Walikota sebagai penguat keberadaan puskesmas tatalaksana KtA belum ada

\section{b. Pedoman penyelenggaraan puskesmas KtA}

Pedoman yang dipakai penyelenggaraan puskesmas tatalaksana $\mathrm{KtA}$ adalah pedoman pengembangan puskesmas mampu tatalaksana yang dikeluarkan Kementrian Kesehatan. Buku pedoman ini hanya dimiliki oleh Puskesmas Anak Air, sedangkan dua puskesmas KtA lainnya belum ada memiliki pedoman tersebut.

\section{c. Sumber Daya Manusia}

Hasil telaah dokumen, observasi, wawancara didapatkan bahwa ketersediaan sumber daya manusia masih belum mencukupi karena karena tenaga terlatih yang ada dimasing-masing puskesmas KtA di Kota Padang masih 1 orang

\section{d. Dana}

Anggaran dana untuk pembiayaan penyelenggaran puskesmas tatalaksana KtA berasal dari dana Bantuan Operasional Kesehatan (BOK) di masing-masing puskesmas $\mathrm{Kt} A$, namun jumlah yang dianggarkan belum mencukupi untuk melaksanakan 
semua kegiatan KtA. Dana yang ada hanya baru bisa dimanfaatkan untuk kegiatan penyuluhan saja.

\section{e. Sarana dan Prasarana}

Hasil telaah dokumen, observasi, wawancara mendalam diketahui jika sarana prasarana untuk mendukung penyelenggaraan puskesmas $\mathrm{KtA}$ masih kurang, karena setiap puskesmas KtA belum memiliki ruangan konseling khusus korban KtA, SOP dan alur penanganan korban $\mathrm{KtA}$ juga belum terlihat $\mathrm{di}$ Puskesmas KtA yang ada di Kota Padang

\section{Komponen Proses}

a. Perencanaan Pelaksanaan puskemas KtA

Perencanaan penyelenggaraan puskesmas tatalaksana KtA belum dilakukan dan belum mengikuti pedoman pengembangan puskesmas tatalaksana KtA seperti puskesmas belum mempunyai rencana kerja, tidak ada pemetaan daerah beresiko KtA, tidak pernah dilakukan sosialisasi di puskesmas, masyarakat dan pada lintas sektor terkait.

\section{b. Pelaksanaan Puskesmas KtA}

Penyelenggaraan puskesmas $\mathrm{KtA}$ belum terlaksana secara komprehensif, karena pelayanan yang diberikan hanya pelayanan kuratif saja, sedangkan pelayana promotif, preventif dan rehabilitatif belum dilaksanakan secara optimal.

\section{c.Pengawasan dan Pengendalian}

Berdasarkan hasil wawancara mendalam dan telaah dokumen didapatkan hasil bahwa sejak ditetapkan menjadi puskesmas tatalaksana KtA belum pernah dilakukan monitoring dan evaluasi khusus baik dari Dinas Kesehatan ataupun dari pimpinan puskesmas KtA Kota Padang.

d.Kemitraan dan jejaring

Berdasarkan hasil wawancara mendalam Jejaring puskesmas $\mathrm{KtA}$ belum terbentuk di Kota Padang, sehingga semua sektor yang terlibat belum terintegrasi dalam melakukan penanganan kekerasan anak di Kota Padang, masing-masing sektor masih berjalan sendiri-sendiri.

\section{Komponen Output}

Penyelenggaraan puskesmas $\mathrm{KtA}$ di Kota Padang pada Puskesmas Andalas, Puskesmas Anak Air dan Puskesmas Air Tawar masih belum optimal, karena belum menjalankan manajemen KtA secara maksimal, hal ini juga disebabkan masih banyaknya kekurangan pada sumber daya manusia, dana, sarana prasarana dan kebijakan Pemerintah daerah juga belum ada.

\section{PEMBAHASAN}

\section{Komponen Input}

a. Kebijakan

Kebijakan pelaksanaan penanganan kekerasan terhadap anak di Kota Padang berdasarkan kepada Peraturan Menteri Kesehatan Nomor 25 Tahun 2014 tentang upaya perlindungan kesehatan anak. ${ }^{13}$ Peraturan Daerah Provinsi Sumatera Barat Nomor 5 tahun 2013. ${ }^{14}$ Peraturan Walikota Padang Nomor 02 tahun 2012. ${ }^{15}$ Kebijakan penyelenggaraan puskesmas $\mathrm{KtA}$ belum diperkuat dengan SK ataupun peraturan walikota, sejak terbentuk di tahun 2016 kebijakan menjalankan puskesmas KtA hanya berdasarkan SK Kepala Dinas Kesehatan Kota Padang tentang penetapan Puskesmas Andalas, Puskesmas Anak Air, dan Puskesmas Air Tawar.

Kebijakan yang ada selama ini belum mampu menggerakan secara optimal pelaksanaan puskesmas $\mathrm{KtA}$, sehingga dirasa perlu dikeluarkan peraturan walikota ataupun SK walikota yang akan mengatur bagaimana sistem pelaksananaan puskesmas $\mathrm{KtA}$ di Kota Padang dan mengatur tentang adanya kerjasama dan koordinasi antar sektor yang terkait dengan puskesmas $\mathrm{KtA}$ atau yang disebut dengan jejaring $\mathrm{Kt} A$, sehingga secara terintegrasi dapat melakukan penanganan terhadap permasalahan kekerasan anak di Kota Padang.

b. Pedoman

Pedoman yang dijadikan acuan untuk penyelenggaraan puskesmas tatalaksana $\mathrm{KtA}$ adalah pedoman pengembangan puskesmas mampu tatalaksana $\mathrm{KtA}$ tentang standar pelayanan kesehatan yang diperoleh korban $\mathrm{KtA}$ mulai penanganan medis, 
medikolegal, psikososial, serta kemitraan dan jejaring.

Pedoman Rujukan Kasus Kekerasan terhadap anak bagi petugas kesehatan yang menjadi acuan bagi petugas dalam menerima dan merujuk kasus kekerasan anak. Kedua pedoman ini dikeluarkan oleh Kementrian Kesehatan.

Jika pedoman ini dijalankan dengan baik, tujuan penyelenggaraan puskesmas KtA akan tercapai, untuk itu disetiap puskesmas KtA mestinya pedoman tersebut ada, dan isinya dipahami oleh semua petugas KtA yang terlibat di puskesmas termasuk pimpinan puskesmas.

\section{c. Sumber Daya Manusia}

Sumber daya manusia yang menjalankan puskesmas KtA adalah tenaga yang sudah dimiliki oleh puskesmas yang terdiri dari dokter, perawat, bidan, analis labor, petugas promkes dan petugas administrasi sesuai dengan standar ketenagaan yang dibutuhkan untuk pelayanan KtA. Setiap puskesmas $\mathrm{KtA}$ juga harus memiliki minimal dua orang tenaga terlatih KtA yang berasal dari tenaga dokter, perawat dan bidan.

Peran tenaga medis dalam penanganan perempuan dan anak korban kekerasan dilakukan pada aspek kuratif dan rehabilitatif melalui penanganan secara medik termasuk menyampaikan informasi melalui informed consent bagi korban rujukan non medis, serta penanggulangannya melalui upaya promotif dan preventif kepada masyarakat umum, masyarakat yang mengalami potensi sasaran tindak kekerasan dan khususnya kepada masayarakat yang telah menjadi korban kekerasan. ${ }^{16}$ Menurut peneliti, kompetensi petugas sangat diperlukan dalam penyelenggaraan puskesmas mampu tatalaksana KtA agar menjadi tenaga yang mampu dan terlatih menangani kasus KtA. Semua itu didapat melalui pelatihan khusus $\mathrm{KtA}$ bagi petugas sehingga petugas mengetahui SOP yang harus dikerjakan dan apa kewajiban sebagai pemberi layanan kesehatan serta mengetahui perlindungan hukum bagi dirinya.

Kompetensi petugas dapat ditingkatkan melalui pelatihan $\mathrm{KtA}$, pelatihan meliputi tatalaksana kasus $\mathrm{KtA}$, konseling/teknik wawancara, cara pengisisan rekam medik, cara pengisian $\mathrm{VeR}$, mekanisme rujukan, pencatatan dan pelaporan, kemitraan dan jejaring.

d. Dana

Biaya kesehatan adalah dana yang harus disediakan untuk menyelenggarakan suatu program atau kegiatan kesehatan. Menurut Adisasmito (2014) pembiayaan kesehatan merupakan tatanan yang dapat menghimpun sebagai upaya penggalian, pengalokasian dan pembelanjaan sumberdaya keuangan secara terpadu dan saling mendukung guna menjamin tercapainya derajat kesehatan masyarakat yang setinggi tingginya. ${ }^{17}$

Kegiatan tatalaksana $\mathrm{KtA}$ di puskesmas penganggarannya dibawah Unit Kesehatan lbu dan Anak, implementasi pemanfaatan BOK dalam upaya peningkatan KIA di puskesmas mencakup beberapa kegiatan yaitu; pendataan sasaran, surveillance, kunjungan rumah, rujukan peserta serta transport petugas. Penanggung jawab KtA bisa mengusulkan adanya anggaran untuk pengumpulan data dan informasi, kunjungan rumah, pendampingan kasus, transport petugas melakukan penyuluhan daan sosialisasi di masyarakat ataupun disektor yang terkait dengan KtA serta anggaran pembuatan leaflet, brosur atau spanduk KtA. Dana BOK yang tersedia bisa dimanfaatkan untuk kegiatan promotif dan preventif. Hal ini senada dengan penelitian yang dilakukan Aridewi et al (2013) yang menyatakan jika dengan adanya dana BOK di puskesmas sangat membantu pelaksanaan upaya promotif dan preventif. ${ }^{18}$

Biaya pengobatan dasar di puskesmas diberikan secara gratis dengan menggunakan APBD, untuk di RSUD Rasidin Padang biaya pengobatan korban KtA dibayarkan dengan jaminan kesehatan yang dimiliki korban, untuk biaya konsultasi korban ke psikolog digratiskan karena layanan psikolog telah disediakan oleh P2TP2A Kota Padang. Sementara untuk biaya pembuatan Visum at Repertum (VeR) ditanggung oleh anggaran kepolisian.

\section{e.Sarana dan Prasarana}

Sarana dan prasarana yang dibutuhkan dalam penanganan $\mathrm{KtA}$ berdasarkan standar puskesmas KtA meliputi: memiliki ruangan pelayanan, alat kesehatan 
dan obat-obatan seperti peralatan diagnostik klinis, sarana konseling/wawancara antara lain buku pedoman, lembar balik, alat permainan edukatif serta sarana lainnya seperti alat perekam, kamera, formulir pencatatatan. Sarana, prasarana dan peralatan yang dibutuhkan oleh rumah sakit adalah Standar Operasional Prosedure (SOP) tertulis, furniture, logistik yang terdiri dari Rape Kit yang berguna untuk mengumpulkan bukti forensik, linen, obat-obatan, perbekalan administratif dan lain-lain. ${ }^{9}$

Sarana dan prasarana harusnya disesuaikan dengan standar yang telah ditetapkan dalam pedoman pengembangan puskesmas mampu tatalaksana KtA, karena sarana dan prasarana akan mendukung terlaksananya penanganan kasus, sehingga mencapai hasil yang optimal dan korban KtA yang datang akan merasa nyaman dalam setiap tindakan yang dilakukan. Menurut peneliti untuk penanganan kasus $\mathrm{KtA}$ memang harus menggunakan sarana dan prasarana yang sesuai standar penanganan KtA, sehingga pelayanan kuratif, preventif, dan promotif serta rehabilitatif dapat diberikan dengan baik oleh petugas KtA.

\section{Komponen Proses}

\section{a. Perencanaan}

Perencanaan pada penyelenggaraan puskesmas tatalaksana $\mathrm{KtA}$ dimulai dengan mengumpulkan data dan informasi, melakukan analisis dan pemetaan sesuai hasil pengumpulan data dan informasi, menyusun rencana kerja, melaksanakan sosialisasi, menyiapkan tenaga pelaksana, menyiapkan petugas konseling dan wawancara serta menyiapkan sarana dan prasarana. ${ }^{9}$ Berdasarkan observasi di puskesmas belum optimal melakukan perencanaan, karena belum menyusun rencana kerja, belum mengumpulkan informasi dan data serta belum membuat peta daerah beresiko $\mathrm{Kt} A$ sesuai hasil pengumpulan data dan informasi, belum optimalnya proses perencanaan tidak terlepas dari peran kepala puskesmas sebagai penanggung jawab teknis di puskesmas.

Perencanaan di puskesmas KtA dimulai dengan mengumpulkan data dan informasi, data dan informasi yang dikumpulkan adalah data kasus yang pernah terjadi dan potensi kasus KtA yang ada diwilayah kerja setempat, kemudian data yang telah dikumpulkan dianalisis dan dilakukaan pemetaan dengan membagi antara wilayah tidak rawan $\mathrm{KtA}$, rawan $\mathrm{KtA}$ dan sangat rawan $\mathrm{KtA}$. Hasil pengumpulan data tersebut puskesmas KtA menyusun rencana kerja terkait dengan intervensi yang akan akan dilakukan dalam penanganan kekerasan terhadap anak diwilayah kerja puskesmas.

Tahap perencanaan selanjutnya adalah dengan melakukan sosialisasi di internal puskesmas melalui kegiatan pertemuan lintas program di puskesmas untuk menyamakan persepsi dan meningkatkan kepekaan petugas terhadap KtA dan membangun komitmen pengembangan puskesmas mampu tatalaksana KtA, kemudian melakukan sosialisasi langsung pada masyarakat sasaran serta melakukan sosialisasi eksternal pada lintas sektor yang terkait dengan jejaring puskesmas tatalaksana $\mathrm{KtA}$. Sosialisasi yang dilakukan di masyarakat dan eksternal puskesmas bertujuan untuk menyampaikan bahwa di Kota Padang telah mempunyai 3 (tiga) puskesmas KtA, berfungsi sebagai puskesmas memberikan pelayanan dan penanganan langsung terhadap korban $\mathrm{KtA}$, puskesmas $\mathrm{KtA}$ juga dijadikan tempat pengaduan pertama apabila terjadi kasus kekerasan terhadap anak.

Pada tahap perencanaan puskesmas KtA juga harus menyiapkan tenaga pelaksana dan konseling puskesmas, tenaga konseling yang dimaksud disini adalah petugas yang memiliki kompetensi penanganan korban $\mathrm{KtA}$ yang didapatkan melalui pelatihan khusus. Konseling yang diberikan kepada anak bertujuan untuk menghilangkan rasa trauma pada anak yang mengalami kekerasan. Penelitian terkait konseling pernah dilakukan Kumala et al (2017) yang mendapatkan hasil jika anak yang mengalami kekerasan mengalami beban psikis yang sangat berat begitu pula beban sosiologisnya, untuk mengurangi beban traumatis maka perlu pendampingan oleh konselor yang sensitif pada korban. Konselor dapat melakukan proses konseling agar anak mampu menemukan jalan keluar dari masalah dan juga mengenali serta mengembangkan potensi diri. ${ }^{19}$ 


\section{b. Pelaksanaan}

Dalam penanganan korban KtA didapatkan kompleksisitas permasalahan sehingga memerlukan penanganan yang komprehensif dan kerjasama lintas sektor. Penanganan korban kekerasan bertujuan untuk memberikan pelayanan menyeluruh bagi korban kekerasan terhadap anak (KtA) ,baik dibidang klinik, medikolegal dan psikososial, disamping pelayanan preventif dan promotif yang juga harus dijalankan oleh puskesmas untuk mengoptimalkan penyelenggaraan puskesma tata laksana KtA.

Pada tahap pelaksanaan tatalaksana $\mathrm{KtA}$ petugas puskesmas harus terlebih dahulu memahami mekanisme pelayanan korban $\mathrm{KtA}$, sistem rujukan pasien korban KtA sampai ke pada tahap pencatatan dan pelaporan kasus KtA. Standar pelayanan kesehatan dalam penanganan kasus $\mathrm{KtA}$ berbeda dengan standar pelayanan pelayanan kesehatan pada umumnya, selain mencakup aspek pelayanan medis secara komprehensif, pelayanan puskesmas KtA juga harus mencakup aspek pelayanan medikolegal dan psikososial, sehingga penanganannya tidak mungkin dikerjakan sendiri tetapi harus bekerjasama dengan lintas program dan sektor terkait melalui jejaring.

Dalam penanganan kasus $\mathrm{KtA}$ petugas harus merahasiakan identitas pelapor, melindungi korban dari pelaku dan upaya bunuh diri, melaporkan kejadian kekerasan kepada pihak yang berwenang dengan persetujuan korban, menyediakan penanganan medis komprehensif, memperhatikan kondisi keluarga merujuk ke jejaring untuk pendampingan paripurna dan penanganan aspek non medis serta mendahulukan kepentingan terbaik bagi anak.

\section{c. Pengawasan Pengendalian}

Merupakan upaya untuk memantau kegiatan agar berjalan sesuai dengan yang direncanakan. Kegiatan meliputi, monitoring dan evaluasi serta pertanggung jawaban.Monitoring bertujuan untuk mengetahui sejauh mana kegiatan sudah dilaksanakan, adanya hambatan dan masalah atau dukungan dalam pelaksanaan pelayanan KtA. Monitoring pelaksanaan pelayanan KtA dapat dilakukan oleh Kepala Puskesmas kepada stafnya melalui pembinaan dan pendampingan, lokarkarya bulanan puskesmas serta menganalisis hasil pencatatan dan pelaporan yang ada. Sedang kan evaluasi seharusnya dilakukan secara berkala melalui rapat staf, lokarkaya bulanan, mini lokakarya, pertemuan lintas sektor setiap 3 (tiga) bulan atau dengan memanfaatkan pelaporan kasus. Hasil monitoring dan evaluasi dapat digunakan untuk menetapkan langkah-langkah perbaikan apabila ditemukan kesenjangan antara target dan realisasi serta untuk menentapkan perencanaan kegiatan tahun berikutnya.

Berdasarkan observasi dilapangan, evaluasi dan monitoring belum optimal pelaksanaannya karena pada saat lokakarya di puskesmas belum pernah dilakukan pembahasan tentang bagaimana pelaksanaan atau berjalannya kegiatan penyelenggaraan puskesmas tatalaksana $\mathrm{KtA}$, pembahasan dilakukan jika terjadi kasus saja, dan itupun tidak dilakukan tindak lanjutnya.

\section{d. Jejaring Kemitraan}

Penanganan kasus KtA tidak mungkin dilaksanakan hanya oleh sektor kesehatan saja karena masalahnya yang multi komplek sehingga harus menggunakan pendekatan multidisiplin yang melibatkan lintas sektor. Agar penanganan didukung oleh semua pihak sesuai tugas pokok, fungsi dan tanggungjawabnya, perlu dikembangkan kemitraan dalam penanganan kasus KtA yang melibatkan semua pemangku kepentingan (Stakeholder), agar kemitraan lebih efektif dibutuhkan suatu jejaring yang didukung oleh semua sektor terkait.

Kemitraan dan jejaring yang terkait dengan penyelenggaraan puskesmas tatalaksana KtA di Kota Padang melibatkan sektor lainnya sperti DP3AP2KB, dinas pendidikan, P2TP2A dan Polresta Kota Padang serta RSUD Rasidin padang sebagai tempat rujukan medis pasien KtA dari puskesmas. Penelitian terkait jejaring KtA dalam melaksanakan perannya pernah dilakukan oleh Anggi (2017) yang melakukan penelitian terkait peran P2TP2A dalam melakukan penanganan kekerasan terhadap anak melalui tiga peran yaitu pelayanana pengaduan, penanganan hukum dan pemulihan. ${ }^{20}$ Peran dari Kepolisian dalam penanganan kekerasan terhadap anak pernah diteliti 
oleh Boentor (2017) yang mendapatkan hasil jika peran kepolisian dalam melakukan tindak pidana kejahatan seksual pada anak dengan melakukan 4 tindakan yaitu dengan melakukan sosialisasi kepada masyarakat, koordinasi dengan masyarakat dan LSM, dan melakukan pemetaan, selanjutnya dilakukan tindakan preventif dengan membentuk POLMAS yang melaksanakan patroli secara teratur, tindakan terakhir adalah tindakan represif yaitu penanggulangan dengan menyelesaikan kasus, memberikan perlindungan kepada saksi dan korban serta menyediakan psikolog untuk mendampingi anak. ${ }^{21}$

Berdasarkan observasi yang telah dilakukan, menurut peneliti jejaring yang terkait dengan penyelenggara puskesmas tatalaksana $\mathrm{KtA}$ ini masih berjalan sendiri sesuai dengan tugas, wewenang dan kompetensi mereka, belum pernah dilakukan koordinasi dengan puskesmas $\mathrm{KtA}$ terkait penanganan kasus kekerasan terhadap anak. Sektor tersebut juga tidak mengetahui jika mereka merupakan bagian dari jejaring penyelenggara puskesmas KtA karena mereka belum pernah tersosialisaikan dengan adanya puskesmas tatalaksana $\mathrm{KtA}$, walaupun sebenarnya sektor sektor terkait sudah menjalan kan tugas dan fungsinya mereka dalam penanganan kekerasan terhadap anak.

\section{Komponen Output}

Hasil penelitian ini menunjukkan bahwa penanganan korban KtA di Kota Padang sudah cukup baik dilakukan oleh Puskesmas Anak Air, karena telah mengaanggarkan dana untuk kegiatan pendampingan kasus, melakukan penanganan medis di puskesmas dengan melakukan konseling dan tindakan medis, pernah melakukan penyuluhan dimasyarakat, dan telah mulai berkoordinasi dengan sektor jejaring KtA yaitu P2TP2A Kota Padang, sedangkan untuk Puskesmas Andalas dan Puskesmas Air Tawar belum optimal dalam menyelenggarakan puskesmas tatalaksana $\mathrm{KtA}$ karena hanya sebatas melakukan penanganan secara medis saja, dan belum sama sekali melakukan upaya preventif, prmotif dan rehabilitatif.

\section{SIMPULAN}

Pada komponen input kebijakan dari Pemerintah Daerah Kota Padang belum ada, yang ada hanya kebijakan Kepala Dinas Kesehatan, Sumber daya manusia, dana, sarana dan prasarana masih belum mencukupi sesuai standar puskesmas tatalaksana KtA. Pada komponen proses manajemen perencanaan,pelaksanaan, pengawasan pengendalian dan jejaring kemitraan belum dilaksanakan secara maksimal. Output dari penyelenggaraan puskesmas KtA di Puskesmas Andalas, Puskesmas Anak Air dan Puskesmas Air Tawar belum optimal.

\section{SARAN}

Diharapkan kepada Walikota Padang untuk dapat mengeluarkan SK atau Pearturan daerah terkait penyelenggaraan puskesmas tatalaksana $\mathrm{KtA}$ dalam upaya penanganan permasalahan kekerasan anak di Kota Padang. Kepala Dinas Kesehatan lebih meningkatkan upaya pembinaan dan pengawasan terhadap pelaksanaan puskesmas KtA. Bagi Kepala Puskesmas Andalas, Anak Air dan Air Tawar agar dapat mengusulkan penambahan tenaga kesehatan yang mengikuti pelatihan $\mathrm{KtA}$, menambah alokasi dana BOK untuk penyelenggaraan puskesmas KtA, melengkapi sarana dan prasarana yang masih kurang serta menjalankan puskesmas KtA sesuai dengan konsep dan manajemen yang telah diatur dalam pedoman pengembangan puskesmas mampu tatalaksana $\mathrm{KtA}$ yang dikeluarkan oleh Kementerian Kesehatan. Upaya kuratif puskesmas harus bekerjasama dan berkoordinasi dengan RSUD DR. Rasidin Padang dan RS Bahayangkara, upaya preventif dan promotif serta rehabilitatif puskesmas harus berkoordinasi dan bekerjasama dengan melibatkan Dinas Pendidikan, P2TP2A dan Kepolisian.

\section{DAFTAR PUSTAKA}

1. Peter CG. Pragmatic foundation social work children and their families. London: Oxford University Press; 2004.hlm.56. 
2. Hillis S, Mercy J, Amobi A. Global prevalence of past years violence againts children. a systematic review and minimum estimate. Pediatrics. 2016; 137(3):e20154079.

3. Kementerian Sosial RI. Survey kekerasan terhadap anak (SKTA) tahun 2013. Jakarta: Kementerian Sosial RI; 2013

4. Dinas Pemberdayaan Perempuan dan Perlindungan Anak Provinsi Sumatera Barat. Laporan data kekerasan terhadap anak provinsi Sumatera Barat tahun 2017. Padang: Dinas PP\& PA Sumbar; 2017.hlm.22-3.

5. Unit Pengaduan Perempuan dan Anak (UPPA) Kepolisian Resort Padang. Laporan pengaduan kekerasan anak. Padang: UPPA Polresta; 2016.hlm.8.

6. Kementerian Kesehatan RI. Pedoman rujukan kasus kekerasan pada anak bagi petugas kesehatan Jakarta: Kementerian Kesehatan RI; 2007.hlm.35-6.

7. Nindya PN, Margaretha R. Hubungan antara kekerasan emosional pada anak terhadap kecendrungan kenakalan remaja. Jurnal Psikologis Klinis dan Kesehatan Mental. 2012;1(02):1-9.

8. Hardisman, Firdawati, Sulreni LN. Model determinan perilaku lelaki seks lelaki di kota Padang Sumatera Barat. Jurnal Kesehatan Andalas. 2018;7(3):305-13.

9. Kementerian Kesehatan RI. Pedoman pengembangan puskesmas tatalaksana kasus terhadap perempuan dan anak. Jakarta: Kementerian Kesehatan RI; 2009.

10. Kementerian Kesehatan RI. Peraturan menteri kesehatan No.68 tahun 2013 tentang kewajiban pemberi layanan kesehatan untuk memberikan informasi atas dugaan kekerasan terhadap anak. Jakarta: Kementerian Kesehatan RI; 2013.

11. Dinas Kesehatan Kota Padang. Profil dinas kesehatan kota Padang. Padang: Dinas Kesehatan Kota Padang; 2017.
12. Sugiyono. Metode penelitian kuantitatif kualitatif dan RD. Bandung: Alfabeta; 2014.hlm.158-9.

13. Kementerian Kesehatan RI. Peraturan menteri kesehatan nomor 25 tahun 2014 tentang upaya perlindungan kesehatan anak. Jakarta: Kementerian Kesehatan RI; 2014.

14. Pemerintah Provinsi Sumatera Barat. Peraturan daerah provinsi Sumatera Barat nomor 5 tahun 2013 tentang perlindungan anak. Padang: Pemerintah Provinsi Sumatera Barat; 2013.

15. Pemerintah Kota Padang. Peraturan walikota Padang nomor 02 tahun 2012 tentang pembinaan dan perlindungan anak. Padang: Pemerintah Kota Padang; 2012.

16. Lawado IS. Implementasi hak konstitusional oleh tenaga kesehatan dalam penanganan perempuan dan anak korban kekerasan. Jurnal Kesehatan dan Budaya. 2014;7(2):1-9.

17. Adisasmito W. Sistem kesehatan. Jakarta: Rajawali Press; 2014 .hlm.120-1.

18. Aridewi A, Kertasurya, Martha I, Sriatmi A. Analisis pemanfaatan bantuan operasional kesehatan dalam upaya peningkatan kesehatan ibu dan anak di puskesmas wilayah kerja dinas kesehatan kabupaten Kudus. Jurnal Manajemen Kesehatan Indonesia. 2013;1(1):32-40.

19. Kumala M, Nurlail IR, Dewi NK. Urgensi peran konselor dalam mengatasi masalah-masalah sosial anak. Prosiding SNBK (Seminar Nasional Bimbingan dan Konseling). 2017;7(2):159-69.

20. Anggi DP. Peran pusat pelayanan terpadu pemberdayaan perempuan dan anak (P2TP2A) kota Pekanbaru dalam penaganan anak yang berhadapan dengan hukum $(\mathrm{ABH})$ tahun 20132014. Jurnal Online Mahasiswa FISIP UNRI. 2017; 4(2):1-13.

21. Boentor. Peranan kepolisian dalam menangani tindak pidana pelecehan seksual terhadap anak di wilayah hukum kepolisisan sektor Mandau-Duri. Jurnal Online Mahasiswa FISIP UNRI. 2017;4(1): 1-15. 